\title{
Uma Experiência de Uso de Jogos Digitais como Ferramentas de Apoio para Aprendizagem de Inglês por Crianças
}

\author{
Paula Basto Levay, Taciana Pontual Falcão, Juliana R. B. Diniz, Rodrigo de Souza \\ Universidade Federal Rural de Pernambuco (UFRPE) \\ Rua Dom Manoel de Medeiros, s/n, Dois Irmãos, CEP 52171-900, Recife - PE - Brasil

\begin{abstract}
This article presents a description of an experience on using digital games in the English teaching and learning process of 4 to 6 year-old children. The main aim of the work was to identify how this digital tool can stimulate pedagogical situations relevant for the learning. A qualitative field research was developed whose data was collected through field notes and audio recorded lessons and analyzed based on the theory. Findings showed that the digital games enabled students to revisit and unconsciously internalize some words in English. Moreover, the games were considered to be a motivational element.
\end{abstract}

Resumo. Este artigo apresenta um relato sobre a utilização de jogos digitais em dispositivos móveis no processo de ensino-aprendizagem de Inglês para crianças entre 4 e 6 anos. $O$ objetivo do trabalho foi identificar como esses jogos podem estimular situações pedagógicas relevantes para a aprendizagem. Foi desenvolvida uma pesquisa de campo qualitativa em que os dados foram coletados através de registros e observações de aulas e interpretados através do confronto com a teoria. Os resultados apontaram que os jogos digitais apresentaram-se como elemento motivacional e possibilitaram aos alunos revisitar palavras e assimilar inconscientemente vocábulos.

\section{Introdução}

A utilização das Tecnologias de Informação e Comunicação (TICs) potencializou as possibilidades de acesso ao conhecimento. As novas TICs promoveram, portanto, mudanças no cenário educacional. Essas mudanças oferecem novas possibilidades de práticas docentes, e podem contribuir para a variação de atividades no processo educativo. Pinto e Botelho (2012) citam Mattar (2010) para observar que as fronteiras entre trabalho, diversão e aprendizagem estão cada vez mais tênues, sinalizando aos educadores a necessidade de repensar "como" ensinam. Dadas as evoluções tecnológicas e a facilidade com a qual as crianças entram em contato com aparelhos eletrônicos, a educação deve buscar a proximidade com a sociedade e a cultura dessas crianças, hoje imersas em um contexto em que as novas tecnologias digitais fazem parte de seu cotidiano. 
Nesse sentido, a utilização de jogos digitais no processo de ensino-aprendizagem nas diversas faixas etárias suporta-se em teorias de aprendizagem e abordagens pedagógicas [Felicia 2012] e ganhou espaço ao longo das últimas décadas. Os jogos digitais se configuram não só como entretenimento, mas também como uma forma de aprendizado. Além disso, a utilização desses jogos em educação ganhou, nos últimos anos, franca importância no cenário de discussões e pesquisas acadêmico-científicas.

Kishimoto (2010) e Macedo (2009), citados por Santos e Bourscheidt (2014) afirmam que no contexto atual, os jogos têm sido considerados recursos didáticopedagógicos valiosos e com comprovadas contribuições no processo de ensino. Desse modo, cabe a realização de pesquisas que provejam novas investigações acerca das contribuições de jogos digitais em diversas áreas de conhecimento, podendo ampliar a disponibilidade de métodos e ferramentas para o professor e o processo educacional.

O estudo relatado neste artigo insere-se em uma pesquisa de mestrado realizada na EADTec- UFRPE e teve por finalidade refletir sobre a inserção dos jogos digitais como ferramenta de apoio pedagógico no ensino-aprendizagem de Inglês para crianças entre 4 e 6 anos. Nesse sentido, buscou verificar de que maneira esse artefato digital pode contribuir para o aprendizado da língua Inglesa, analisando aspectos como interesse em participar da aula, e assimilação e revisitação de vocabulário. Avaliamos a utilização de quatro jogos digitais, usados em um dispositivo móvel na escola.

O artigo está estruturado da seguinte forma: na seção 2, são apresentados alguns aspectos que influenciam o aprendizado de Inglês para crianças; na seção 3, discute-se o estado da arte em relação aos jogos digitais na educação; na seção 4, apresenta-se a metodologia de pesquisa; na seção 5 são apresentados os resultados obtidos; na seção 6, são expostas as conclusões e na seção 7, encontram-se as referências que alicerçaram teoricamente este trabalho.

\section{Ensino e Aprendizagem de Inglês para Crianças}

\subsection{Aquisição de Linguagem}

A teoria geral do linguista Stephen Krashen (1985) influenciou fortemente estudos e pesquisas acerca da aquisição e aprendizagem de línguas estrangeiras. Sustentada por cinco hipóteses, essa teoria busca explicar como acontece a aquisição de uma língua estrangeira.

A primeira hipótese trata da distinção entre aprendizagem e aquisição (acquisitionlearning hypothesis). Segundo o modelo de Krashen, a aprendizagem corresponde a um processo consciente, resultante de um conhecimento formal acerca das estruturas da língua. Por outro lado, a aquisição acontece por meio de um processo automático, que se dá no nível subconsciente, fruto de interação em situações reais de convívio humano em ambientes da língua e da cultura estrangeira e na exposição à língua.

Para o autor, a aquisição é considerada um aprendizado natural, que ocorre, sobretudo, durante a infância. Em crianças pequenas, a aquisição acontece de maneira semelhante ao processo de aquisição da língua materna. Como na língua-mãe, as crianças têm acesso à outra língua, nesse caso ao inglês passivo, presente nas teclas dos computadores e controles remotos, em músicas, filmes, propagandas e jogos digitais e de videogame. Primeiramente, elas passam pela fase de ouvir, de assimilação, depois, elas começam a expressar aquilo que internalizaram passivamente. Nesse processo de internalização passiva, o aprendiz desenvolve familiaridade com a característica fonética da língua, sua estrutura e seu vocabulário. A aquisição é responsável pelo entendimento oral. Quanto mais a criança é exposta à língua, mais familiarizada ela se tornará com os fonemas e com a entonação. 
Outra hipótese da teoria do linguista é a do filtro afetivo (affective filter hypothesis), defendido pelo autor como o primeiro obstáculo com o qual a linguagem se depara antes de ser processada e internalizada. O filtro afetivo parte do processo interno no qual se configuram os estados emocionais, as atitudes, as necessidades, a motivação do aprendiz ao aprender uma língua.

A hipótese do filtro afetivo, portanto, considera que um número de variáveis afetivas tem um papel facilitador na aquisição de uma língua estrangeira. Estas variáveis afetivas incluem: motivação, autoconfiança e ansiedade. Aprendizes motivados, confiantes e com baixa ansiedade tendem a ser bem sucedidos no processo de aquisição de uma outra língua. Esses aprendizes teriam um baixo filtro afetivo e absorveriam insumo com muito mais facilidade, enquanto que alunos tensos, ansiosos e com baixa autoestima e menos motivação, tenderiam a elevar o nível de seu filtro afetivo e a formar um tipo de bloqueio mental, diminuindo, assim, sua capacidade de absorção de insumo. $\mathrm{O}$ filtro afetivo, quando elevado, mesmo o aluno compreendendo o que lê ou ouve, pode inibir o processo de aquisição [Voluz 2013]. Para Voluz (2013, p. 33) quando "o filtro é reduzido, a língua será adquirida com maior facilidade e eficácia”.

Em qualquer aspecto da educação, é importante que se crie um ambiente seguro e convidativo no qual os alunos possam aprender. Na aprendizagem de línguas, isso pode ser especialmente importante uma vez que para se assimilar ou produzir linguagem, os aprendizes precisam se sentir confiantes para cometer erros e se arriscar. Rocha (2006) afirma que fatores como confiança, motivação, autoestima e personalidade influenciam decisivamente no processo de ensino e aprendizagem de língua estrangeira. A motivação, para teóricos como Piaget (1982), é um dos elementos principais para o desenvolvimento de um conhecimento.

\subsection{Revisitação de Palavras}

Para assimilação de linguagem em língua inglesa, crianças pequenas precisam revisitar um mesmo conteúdo diversas vezes. $\mathrm{O}$ vocabulário e/ou estruturas introduzidos a esses alunos precisam ser trabalhados inúmeras vezes e também de diferentes formas [Brumfit, Moon and Tongue 1991]. Quando crianças pequenas são expostas a uma linguagem, elas precisam ver e rever, repetir mais de uma vez até que elas, de fato, comecem a produzi-la.

De acordo com Harmer (2007) a repetição sempre esteve presente no aprendizado de uma língua. No entanto, repetir, no sentido de reproduzir alguma coisa diversas vezes, uma vez após a outra não é, de fato, o que as crianças precisam. O que os aprendizes de uma língua precisam é de contatos diversos com a linguagem através de diferentes atividades, por exemplo. Dentro dessa perspectiva, Reilly e Ward (2008) afirmam que embora as crianças possam parecer não ter dificuldade para entender e usar a linguagem que está sendo apresentada, isso não significa que eles aprenderam, e apenas a exposição repetida e reciclagem ao longo de muitas lições irá garantir que elas sejam capazes de usar essa linguagem de forma independente [Reilly and Ward 2008]. Harmer (2007) diz que se os alunos virem ou escutarem uma linguagem uma vez, mesmo quando a notam, podem esquecê-la. Mas quanto mais eles se deparam com essa linguagem, quanto mais repetidos encontros eles tiverem com ela, mais chances terão de lembrar e estarem aptos a usá-la [Harmer 2007].

Não é possível afirmar que a criança 'aprendeu' ou 'assimilou' definitivamente uma palavra ou uma estrutura após algumas exposições em aulas. Após algumas aulas, as crianças podem estar aptas a produzir a linguagem. No entanto, é preciso revisitar em momentos temporalmente distintos. Sokmen (1997) menciona a importância de se fornecer 
aos alunos vários encontros com vocábulos previamente vistos porém sempre através de uma variedade de atividades ou jogos e em diferentes contextos.

\section{Jogos Digitais como Veículos para Aprendizagem}

A relevância dos jogos digitais para a educação tem sido demonstrada através de diversas obras e pesquisas na área. O crescimento do estado da arte acerca do tema aponta para uma mudança na perspectiva de jogos digitais, pois Felicia (2012) e Rapini (2012) afirmam que esses jogos sempre tiveram associados à sua imagem um estigma negativo e são por vezes classificados como uma atividade violenta e irracional. No contexto escolar, os pais podem acreditar que os jogos digitais são perda de tempo e alguns professores podem enxergar esses jogos como inimigos que podem 'roubar' o tempo dos alunos.

Alguns trabalhos recentemente publicados apontam resultados e ideias em concordância acerca dos benefícios desses jogos para a aprendizagem. Ferreira et al. (2014, p.306) afirmam que "os jogos eletrônicos educativos têm se tornado cada vez mais presentes, como uma ferramenta lúdica no processo de ensino e aprendizagem". Jesus et al. (2014) descrevem métodos aplicados e experiências adquiridas na utilização do desenvolvimento de jogos eletrônicos para motivar alunos de diferentes níveis de ensino a permanecer nos cursos de computação. $\mathrm{O}$ estudo realizado mostra que os autores consideraram jogos digitais elementos potencializadores no aumento da motivação dos alunos.

Para Felicia (2012) e Rapini (2012), jogos digitais, quando jogados no tempo, ambiente, e contexto adequados, podem ser considerados uma atividade segura e gratificante. Além disso, os autores afirmam que uma das maiores qualidades dos jogos digitais é engajar os alunos aumentando a motivação para aprender ou prestar atenção. Eles auxiliam na construção da autoconfiança e na incrementação da motivação no contexto da aprendizagem [Hopf et al. 2005 apud Aguiar 2008].

Como discutido na seção anterior, a motivação é considerada por teóricos como Piaget (1982) um dos elementos principais para o desenvolvimento de um conhecimento. Dentro dessa mesma perspectiva, Gros (2007) considera que a aprendizagem é vista por muitos como uma obrigação para as crianças. Entretanto, quando uma atividade envolve prazer, diversão, motivação, interesse, o indivíduo é capaz de dedicar a ela uma grande parte de tempo e esforço. Como jogos digitais envolvem muitos fatores motivacionais, poderiam ser utilizados por educadores para auxiliar na aprendizagem de conteúdos difíceis de tratar em salas de aula tradicionais. O trabalho conduzido por Neto e Fonseca (2013), por exemplo, apresenta as oportunidades para revisão de conteúdos vistos em sala, oferecidas aos alunos a partir de um jogo digital móvel em aulas de Matemática.

No que diz respeito à relação entre jogos digitais e o aprendizado de uma língua estrangeira, Ishida et al. (2012) defendem que, com os recursos de celulares, computadores, tablets e televisores, as crianças estão constantemente imersas em um mundo de simulação. Assim, práticas que utilizam os jogos digitais atendem ao seu perfil e se configuram como instrumentos que podem potencializar a aprendizagem de uma língua estrangeira.

Motteram (2013) aponta que muitos professores estão englobando os interesses dos alunos por jogos digitais e estão criando oportunidades de praticar a língua inglesa através do uso desses jogos em contextos educacionais. $\mathrm{O}$ autor diz que jogos digitais em particular estão se tornando cada vez mais populares por facilitarem a aquisição de linguagem e desenvolvimento de habilidades da língua além de ajudarem com aquisição de vocabulário. Além disso, esses jogos podem requerer dos alunos que internalizem estruturas da língua. Isso dá aos alunos oportunidade para praticar a gramática. Outras contribuições dos jogos para aquisição de vocabulário em língua Inglesa são apontadas por Uzun (2009), Chen e Yang 
(2013) e Ruphina e Liu (2011). De forma semelhante aos estudos citados, buscamos investigar como os jogos podem contribuir para assimilação de vocabulário. No entanto, diferentemente, nosso estudo propõe uma análise do impacto desses jogos com alunos em uma faixa etária mais nova, os quais podem assimilar a língua de maneira diferente da de aprendizes em outras idades, requerendo diferentes análises e investigações.

\section{Metodologia}

Para a realização do estudo, foi utilizado o método qualitativo [Liberali and Liberali 2011] e desenvolvida uma pesquisa de campo com alunos de uma escola de idiomas localizada na cidade do Recife, Pernambuco. A interpretação é a mola propulsora da pesquisa qualitativa e a compreensão é um dos pilares desse paradigma. De acordo com Dornyei (2006), a pesquisa qualitativa é fundamentalmente interpretativista, o que significa que os resultados são o produto da interpretação subjetiva do pesquisador em relação aos dados.

Os sujeitos desse estudo foram 29 crianças, sendo 13 meninas e 16 meninos entre 4 e 6 anos, alunos de quatro turmas de uma mesma instituição, os quais foram conduzidos a jogar jogos digitais em um tablet ao longo de três aulas. As crianças foram apresentadas à atividade e receberam o equipamento para jogarem cada jogo individualmente em um tempo de quatro a cinco minutos. Todavia, os outros alunos podiam ficar ao lado e ajudar quando desejassem.

Os jogos selecionados para a condução da pesquisa foram: Monkey Lunch Box, Edukitty Preschool, Mingoville Preschool e Fun English, encontrados na AppStore e disponíveis para aparelhos móveis com sistema operacional IOS. Os jogos apresentam em suas telas o mesmo grupo de palavras que se repetem em atividades diversificadas como atividades de ouvir e reconhecer vocábulos, jogo da memória, categorização, e quebra-cabeças.

Objetivamos identificar as contribuições que esses jogos digitais podem trazer para o ensino-aprendizagem de inglês quando utilizados por alunos. Essas possíveis contribuições foram investigadas a partir da identificação das seguintes variáveis: (1) engajamento e interesse em participar da atividade e (2) revisitação de palavras e compreensão oral de vocábulos.

Para identificação da primeira variável, o critério utilizado foi a análise dos comentários dos alunos durante o momento da atividade de jogar um jogo digital. Para coletar os dados da revisitação de palavras, a professora perguntou aos alunos os vocábulos vistos nos jogos. Para coleta dos dados da identificação da compreensão oral foi anotada e avaliada a corretude das palavras pronunciadas pelas crianças As palavras foram sendo ditas a partir de intervenções da professora e algumas de maneira espontânea. A professora interveio três ou quatro vezes no momento de cada aluno jogar, com as perguntas: "O que você ouviu?", "Vamos ouvir?" e "O que o joguinho falou?". Não houve uma métrica numérica/ quantitativa para coleta e análise da compreensão dos alunos por sabermos que em alguns momentos os alunos não responderiam por estarem concentrados. As palavras ditas pelas crianças foram postas em uma tabela (Seção 5.2) para ilustrar a oportunidade de ouvir a língua Inglesa exemplificada com a compreensão e consequente correta reprodução dos vocábulos pelos alunos.

Após a identificação das variáveis, para análise das possíveis contribuições para o ensino e aprendizagem de Inglês, foi realizado um confronto entre o referencial teórico acerca da aprendizagem de Inglês e os dados coletados na experiência de uso 
dos alunos. Foram considerados alguns aspectos que influenciam o processo de aquisição da língua e que contribuem para o desenvolvimento do aprendiz enquanto falante. Essas contribuições serão descritas na seção de resultados.

\section{Resultados}

Os resultados obtidos neste estudo serão divididos em tópicos intitulados com algumas falas de alunos relacionadas à discussão.

\section{1. “ É muito massa né?"- Interesse e Engajamento dos Alunos para Participar da Aula}

A pesquisa foi iniciada com a apresentação do dispositivo móvel para os alunos. Um dos objetivos da professora era identificar a reação dos alunos assim como a motivação e engajamento para a utilização do tablet e para jogar um jogo digital. Em todas as turmas, pode-se observar o elemento que aumenta o interesse pela atividade trazido pelo jogo digital. Os excertos das aulas em todas as turmas apontam esse resultado (Figura 1).

\section{Aluno 3 turma 2: Quero o mesmo jogo}

Aluno 1 turma 2: Depois pode ser eu de novo? Depois dele pode ser eu?

Aluno 4 turma 2: Tia, depois dele sou eu né?

Aluno 2 turma 2: A gente vai jogar outro?

Aluno 3 turma 3: É a minha vez?

Aluno 2 turma 3: Posso passar mais uma fase?

Aluno 3, turma 2: Teacher, deixa eu de novo.

Aluno 3, turma 4: Tia, eu quero ir nos três.

Aluno 3 turma 1: Teacher, eu.

Aluno 1 Turma 4, teacher, quero ir no terceiro.

Aluno 3 turma 4: É muito bom.

Aluno 3 Turma 4: Pode ser eu?

Aluno 7 turma 4: Eu quero.

Aluno 1 turma 4: Sou eu.

Aluno 4 turma 4: Depois pode ser eu?

Aluno 3 turma 4: Quero ir no terceiro.

Aluno 8 turma 4: Depois dela pode ser eu?

No segundo dia em que a professora leva o tablet, os alunos a viram com o tablet na mão e, em turmas diferentes, foram coletadas algumas falas dos alunos acerca do interesse em utilizar o equipamento.

Aluno 1, turma 2: Tia, hoje tem joguinho é?

Aluno 3 turma 2: Eu quero também.

Aluno 4 turma 2: Depois você me dá?

A Turma 1 na primeira vez jogando o jogo Monkey Lunch Box Todos os alunos ao redor do celular, uns ajudando os outros. Aluno 3, turma 1: Pra mim, pra mim.

Aluno 1 turma 1 : Cada um pode jogar duas vezes?

Aluno 7 turma 3: É minha vez.

Aluno 3 turma 3: Tia, é minha vez? Posso passar mais uma fase? Já posso ir?

Aluno 5, turma 3: É muito massa né?

Aluno 5 turma 3: Depois dela é eu primeiro.

Nesse momento, todos olhando para o jogo. Na experiência com o Jogo EduKitty Preschool, o primeiro aluno começa a jogar e todos os outros foram ver. Aluno 1 turma 1 comemora bastante, representando o entusiasmo para realizar a atividade de jogar o jogo digital 
A motivação, nesse caso, a demonstração de interesse em se engajar para participar da atividade, é fundamental para o processo de aquisição de língua estrangeira assim como postulou Piaget (1982), e foi observada a partir da quantidade de vezes em que praticamente todos os alunos fizeram comentários que mostram seu engajamento na atividade e interesse em jogar de novo. Esse resultado confirma o que foi apontado por Rapini (2012) e Felicia (2012). Segundo os autores, um dos maiores benefícios dos jogos digitais é a motivação para aprender ou prestar atenção. No estudo, observou-se o envolvimento dos alunos para participar da atividade, no caso, para fazer uso do tablet $\mathrm{e}$ jogar o jogo digital. Dessa forma, eles já iniciaram o processo de aprendizagem, inconscientemente, preparados para a aquisição de um novo conhecimento. Considerando as ideias de Krashen (1985) que alunos 'mais relaxados' aprendem mais facilmente - the Affective Filter hypothesis (Seção 2) - as barreiras que poderiam existir são quebradas a partir desse interesse para iniciar a atividade e dessa sensação de conforto e relaxamento, consequente da motivação, apresentada pelos alunos.

\section{2. "Teacher, o joguinho falou 'orange'. Eu já sabia." - Contribuição dos Jogos para Revisitação de Palavras e Assimilação de Vocabulário}

Os excertos apontados nas figuras 2 e 3 apresentam alguns dados coletados através das observações da pesquisadora e as falas dos alunos que correspondem à revisitação de palavras dos aprendizes. Com os dados coletados, podemos verificar que os alunos já conheciam os vocábulos mencionados e puderam revistá-los ao jogar o jogo. Considerando os postulados de Brumfit, Moon e Tongue (1991), Harmer (2007) e Reilly e Ward (2008), o aprendiz deve ter oportunidade de rever estruturas e vocabulários em momentos temporalmente distintos para que, de fato, os adquira e se aproprie desse conhecimento. Foi possível, então, verificar que os jogos digitais puderam contribuir para consolidação e possível aquisição de vocabulário previamente visto.

Teacher: O que mais tinha no game?

Aluna 1, turma 3. "Eu ouvi apple, teacher. Eu já sabia porque eu ouvi num jogo que tinha no tablet da minha mãe mas apagou...

Aluna 7 turma 3: Orange. Orange é laranja.

Figura 2 - Observações da turma 3 que representam a revisitação de vocábulos.

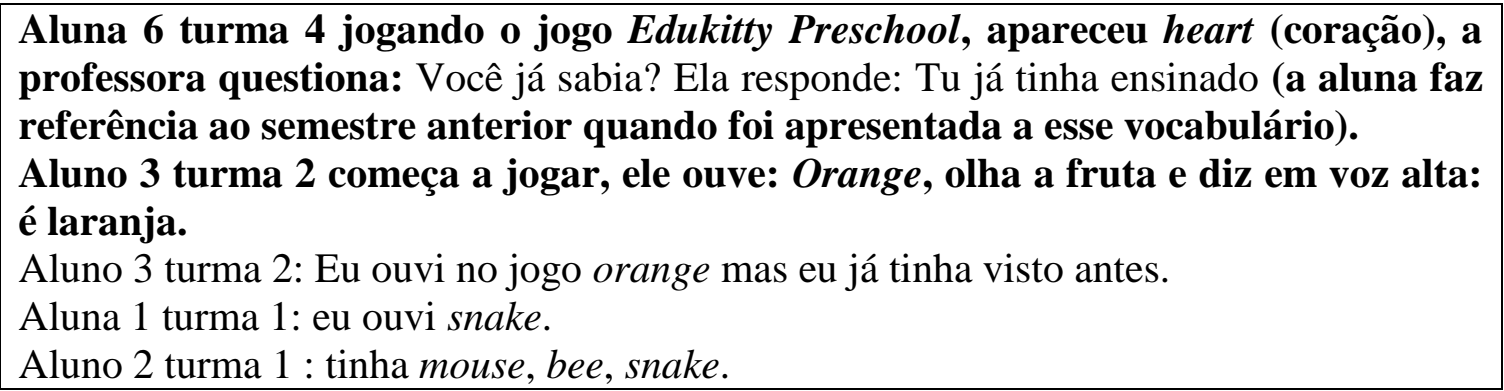

Figura 3 - Observações nas turmas 4, 2 e 1 que representam a revisitação de vocábulos.

Os resultados apontaram ainda que jogar um jogo digital em Inglês foi uma oportunidade de estar exposto à língua e ouvir corretamente a pronúncia das palavras. $\mathrm{O}$ jogo funcionou como exemplo de 'falante' da língua. Desse modo, configurou-se como oportunidade de o aluno escutar a língua inglesa. A partir do confronto com a teoria de Krashen (1985), que defende que as crianças de maneira inconsciente introduzem 
vocábulos quando imersos em contextos de língua Inglesa, no qual têm oportunidade de ouvir a língua, conclui-se que o ato de jogar pode contribuir para introdução de vocábulos e consequente aquisição de linguagem em Inglês.

O fato de os alunos repetirem espontaneamente as palavras pode ser considerado ainda uma contribuição do jogo para que o aluno utilize a língua, ou seja, para que os alunos falem.

A figura 4 mostra as palavras pronunciadas pelos alunos enquanto jogavam e que ilustram o resultado acima exposto. Essas palavras foram ditas pelos alunos na segunda aula, na qual jogaram o jogo Monkey Lunch Box pela segunda vez. Essas palavras foram ditas também ao longo das outras aulas mesmo quando o objetivo da observação não era primordialmente analisar esse aspecto de assimilação e compreensão oral.

\begin{tabular}{|c|c|}
\hline ALUNO & PALAVRAS FALADAS \\
\hline Aluna 1 turma 1 & Plusberry, cherry, orange, red \\
\hline Aluno 2 turma 1 & Nectarine, kiwi, four, lemon \\
\hline Aluno 3 turma 1 & One, two, three, nectarine, apple, pineapple, take a sticker, gray \\
\hline Aluno 4 turma 1 & Take a sticker, red, yellow, strawberry \\
\hline Aluno 5 turma 1 & Cherry, yellow, kiwi, pineapple \\
\hline Aluno 6 turma 1 & Plusberry, orange, purple. \\
\hline Aluno 1 turma 2 & One, two, three, kiwi, different \\
\hline Aluno 2 turma 2 & One, two, three, four, five, banana, red, yellow, purple, orange \\
\hline Aluno 3 turma 2 & Lime, grape, banana, watermelon, square \\
\hline Aluno 4 turma 2 & Lemon, lime, grape, Orange \\
\hline Aluno 5 turma 2 & Yellow, kiwi, plusberry, orange, banana, different \\
\hline Aluno 6 turma 2 & Plusberry, one, honeydew, two, three \\
\hline Aluno 1 turma 3 & Apple, apple, two \\
\hline Aluno 3 turma 3 & Grape, lemon \\
\hline Aluno 4 turma 3 & Three, lime, lemon, strawberry \\
\hline Aluno 5 turma 3 & Take a sticker, lime, lemon, two, yellow, watermelon, grape, \\
\hline Aluno 6 turma 3 & Apple, two, red, sticker \\
\hline Aluno 7 turma 3 & Orange, yellow, seven, two, grape, apple \\
\hline Aluno 8 turma 3 & Banana, sticker \\
\hline Aluno 1 turma 4 & $\begin{array}{l}\text { Orange, banana, purple, lemon, six, grape, apple, nectarine, } \\
\text { orange }\end{array}$ \\
\hline Aluno 2 turma 4 & Banana, grape, lime, lemon, apple \\
\hline Aluno 3 turma 4 & Triangle, different, frog, \\
\hline Aluno 4 turma 4 & Frog \\
\hline Aluno 5 turma 4 & Two, orange, different, square, triangle \\
\hline Aluno 6 turma 4 & Strawberry \\
\hline
\end{tabular}




\section{Aluno 7 turma 4 Apple, apple, on, two, three, four, five. \\ Aluno 8 turma 4 Nectarine, triangle, square \\ Figura 4 - Palavras repetidas pelos alunos ao longo das experiências com os jogos digitais.}

Apesar de não termos realizado uma análise numérica/ quantitativa da compreensão oral dos alunos, a quantidade de palavras pronunciadas corretamente pelas crianças aponta que elas estavam ouvindo efetivamente a língua. Apenas dois alunos falaram somente uma palavra e um aluno não repetiu nenhuma palavra. Ao mesmo tempo em que completavam as atividades, ouviam a língua inglesa, não estando jogando de maneira automática, sem ouvir o que estava sendo dito.

Os jogos digitais selecionados foram, portanto, uma oportunidade para o aluno estar exposto à língua. Desse modo, esses jogos podem funcionar como recurso que pode contribuir para a aquisição de vocabulário e linguagem assim como histórias, músicas, rimas, recursos utilizados no processo de ensino de Inglês para crianças.

\section{Conclusões}

De acordo com os resultados obtidos na experiência realizada, concluímos que a partir dos jogos digitais houve a possibilidade de assimilação de vocabulário e pronúncia e a possibilidade de revisitação de palavras pelos aprendizes, que através de palavras ditas mostraram ter revisto e assimilado inconscientemente vários vocábulos. Pode-se apontar, ainda, que a utilização dos jogos digitais foi um elemento motivacional dentro do contexto da sala de aula uma vez que os alunos demonstraram grande engajamento e interesse em participar das atividades. Esse engajamento pode contribuir para a aquisição da língua tendo em vista a contribuição do envolvimento do aluno para a quebra de possíveis barreiras para a aquisição do idioma.

A partir dos resultados evidenciados neste artigo, destacamos, então, que os jogos digitais, quando adequados para o público-alvo, apresentam contribuições para o ensino-aprendizagem de Inglês, o que evidencia a possibilidade de adotar essa nova tecnologia como ferramenta pedagógica, uma vez que, os alunos envolvidos na pesquisa possuem competências digitais e, então, não enfrentam dificuldades para utilizar esse tipo de artefato tecnológico. Além disso, concluímos que os jogos tornaram a experiência de aquisição da língua mais natural e divertida.

Trabalhos futuros decorrentes desse estudo visam realizar uma análise comparativa entre os jogos com vistas a identificar quais jogos despertam mais interesse nos alunos e apresentam maior possibilidade de assimilação e aquisição de vocábulos. Além disso, pretendemos acompanhar a evolução de um grupo de alunos acerca de vocabulário e pronúncia a partir da realização das atividades dos jogos digitais em comparação a um grupo que utilize outra ferramenta mais tradicional. Por fim, pretendemos verificar a compreensão oral e de sentido dos alunos através da observação da resposta às atividades dos jogos, com fins de avaliar esse artefato como instrumento avaliativo alternativo para o professor.

\section{Referências}

Brumfit, C.; Moon, J.; Tongue, R. (1991) "Teaching English to children: from practice to principle". Collinselt: London

Felicia, P. (2012) "Digital Games in schools: a handbook for teachers.” European Schoolnet. 
Ferreira, M.; Santos, H.; Oliveira, E.; Lucena, A. (2014) "NiceTown- Um jogo eletrônico para ensino da Educação Ambiental. Anais do Workshop de Informática na Escola WIE.

Gros, B. (2007) "Digital Games in Education: The Design of Games-Based Learning Environments." Journal of Research on Technology in Education, 2007, 40(1), $23-38$.

Harmer, J. (2007) “The practice of English Language Teaching”. Fourth Edition. Longman: Cambridge, UK.

Holden, S. (1980) “Teaching Children.” London: Modern English Publications.

Ishida, H.; Amarante, M. F. (2012) "Representação e práticas identitárias de professores e alunos no discurso de jogos digitais educacionais para o ensino de Inglês para crianças". Anais do XVII Encontro de Iniciação Científica- PUC/ SP.

Jesus, A.; Gonçalves, D.; Ferreira, L. (2014) "Aplicação de jogos digitais como um meio de motivação em diferentes níveis de Ensino de Computação”. Anais do Workshop de Informática na Escola - WIE.

Krashen, S. (1985) “The input hypothesis: Issues and implications”. NY: Longman.

Kishimoto, T. K. (Org.) (2010) “Jogo, Brinquedo, Brincadeira e a Educação”. São Paulo: Cortez.

Levay, P. (2015) "Jogos digitais no ensino e aprendizagem de inglês para crianças". Dissertação de Mestrado- EADTEC-UFRPE.

Liberali, F.; Liberali, A. (2011) "Para pensar a metodologia de pesquisa nas ciências humanas". PUC- São Paulo.Macedo, L. (2009) "Os Jogos e o Lúdico na Aprendizagem Escolar”. São Paulo: Casa do Psicólogo.

Mattar, J. (2009) “Games em educação: como os nativos digitais aprendem” 1 ed. São Paulo: Pearson Prentice Hall.

Neto, J.; Fonseca, F. (2013) "Jogos educativos em dispositivos móveis como auxílio ao ensino da Matemática.” Novas Tecnologias na Educação. V. 11 No 1. CINTED-UFRGS.

Peirce, N. (2013) "Digital Game-Based Learning for early childhood.” Learnovate Centre: Irlanda.

Piaget, J. (1982) "Play, dreams and imitation in childhood" Norton library (Vol. 4, pp. 316339). Norton.

Pinto, I.; Botelho, S. (2012) “Ambientes Tecnológicos Lúdicos de Autoria (ATLA): criando espaços de ensino e aprendizagem". Revista Brasileira de Informática na Educação, Volume 20, Número 3.

Rapini, S. (2012) "Beyond Textbooks and Lectures: Digital Game- Based Learning in STEMS Subjects. Center for Excellence in Education. McLean:Virginia.

Santos, C.; Bourscheidt, V. (2014) "AdapterGame e suas contribuições na concepção de jogos digitais”. Anais do Workshop de Informática na Escola - WIE.

Sokmen, A. (1997) “Current Trends in Teaching Second Language Vocabulary”. Cambridge: Cambridge University Press. 